\title{
Gastrointestinal helminths of lizards (Reptilia: Squamata) from Egypt
}

\section{Original Article}

\author{
Rasha A Elmahy, Samar F Harras
}

Department of Zoology, Faculty of Science, Tanta University, Tanta 31527-Egypt

\begin{abstract}
Background: Despite the fact that Egypt contains a large number of lizard species, yet there is little knowledge recorded regarding the helminth fauna infecting this group of hosts. A parasitological study on gastrointestinal helminths of lizards was carried out during Summer (August) and Autumn (September and October), 2014 and 2015, respectively.

Objective: This study aims to update information on helminth parasites that infect lizards in Egypt.

Material and Methods: Seven species of lizards, Pseudotrapelus sinaitus Heyden, 1827; Trapelus mutabilis Merrem, 1820 (Agamidae); Tarentola mauritanica mauritanica Linnaeus, 1758 (Phyllodactylidae); Tropiocolotes tripolitanus Peters, 1880 (Gekkonidae); Acanthodactylus boskianus Daudin, 1802 (Lacertidae); Chamaeleo africanus Laurenti, 1768 (Chamaeleonidae); and Varanus niloticus Linnaeus, 1766 (Varanidae), were collected from several parts of Egypt. These hosts were dissected and examined for gastrointestinal helminth. The collected helminths were fixed in $70 \%$ ethanol, stained with carmine and examined by using an Olympus CX31 microscope and a Zeiss Stemi 2000-C microscope.

Results: The total prevalence of infection with helminths was 35.9\%. The study recorded 16 species of helminths recognised as: six species of digenea [Prosthodendrium obtusum (Looss, 1896) Bhalerao, 1936, Pleurogenoides tener (Olsson, 1876) Travassos, 1921, Anchitrema sanguineum (Sonsino, 1894) Looss, 1899, Cyclorchis varani Price, 1936, Mesostephanus milvi Yamaguti, 1939 and Haplorchis pumilio (Looss, 1896) Looss, 1899], four species of cestodes [three adults, Oochostrica mutabili Morsy et al., 2013, Duthiersia fimbriata Diesing, 1854 and one unidentified cestode and one tetrathyridia of Mesocestoides spp.] and six species of nematodes [Parapharyngodon micipsae Seurat, 1917, Pharyngodon inermicauda Baylis, 1923, Abbreviata leptosome Gervais, 1848, Thubunaea pudica Seurat, 1914, Tanqua tiara (von Linstow, 1879) Blanchard, 1904 and Spinicauda sonsinoi (Linstow, 1894) Travassos, 1920].

Conclusion: This study documents 10 new host and 10 new locality records in Egypt and distinguishes between studied material and reported descriptions. These findings add significantly to the present information on helminths infecting lizards in Egypt.
\end{abstract}

Keywords: Cestode, digenea, Egypt, helminths, lizards, nematode.

Received: 18 June, 2019, Accepted: 20 July, 2019.

Corresponding Author: Rasha A Elmahy, Tel.: +20 1001709806; E-mail: rasha.elmahi@science.tanta.edu.eg

Print ISSN: 1687-7942, Online ISSN: 2090-2646, Vol. 12, No. 2, Ausgust, 2019.

\section{INTRODUCTION}

Egypt is in the north-eastern part of the continent of Africa with roughly one million square kilometres $(1,019,600 \mathrm{~km})$ of surface area. The country constitutes four major terrestrial physiographic regions (the Nile Valley, Western Desert, Eastern Desert, and Sinai) and two marine regions (Mediterranean and Red Sea) ${ }^{[1,2]}$, besides the River Nile. Lizards are some of the most successful wildlife hosts in Egypt $\mathrm{t}^{[2]}$. They have a large distribution range throughout different parts of Egypt. Only few studies on the helminth fauna of lizards have been previously reported ${ }^{[3-9]}$. The aim of our survey is to identify and update the knowledge of the helminth fauna of lizards in Egypt.

\section{MATERIAL AND METHODS}

This parasitological study on gastrointestinal helminths of lizards was conducted during Summer
(August) and Autumn (September and October), 2014 and 2015, respectively. We collected seven species of lizards: Sinai agama, Pseudotrapelus sinaitus Heyden, 1827 from South Sinai $\left(28^{\circ} 33^{\prime} 23^{\prime \prime} \mathrm{N}, 33^{\circ} 58^{\prime} 28^{\prime \prime} \mathrm{E}\right)$; Desert agama, Trapelus mutabilis Merrem, 1820 from El-Dabaa desert $\left(30^{\circ} 1^{\prime} 36^{\prime \prime} \mathrm{N}, 28^{\circ} 26^{\prime} 9^{\prime \prime} \mathrm{E}\right)$ and Al Magarah, Al Hosnah, North Sinai $\left(30^{\circ} 36^{\prime} 51^{\prime \prime} \mathrm{N}\right.$, $33^{\circ} 43^{\prime} 18^{\prime \prime} \mathrm{E}$ ); Moorish gecko, Tarentola mauritanica mauritanica Linnaeus, 1758; Northern sand gecko, Tropiocolotes tripolitanus Peters, 1880 from 11th district near 6th October desert $\left(29^{\circ} 53^{\prime} 18^{\prime \prime} \mathrm{N}\right.$, $30^{\circ} 50^{\prime} 21^{\prime \prime} \mathrm{E}$ ); Bosk's fringe-fingered lizard or Bosc's fringe-toed lizard, Acanthodactylus boskianus Daudin, 1802 from Dahshour $\left(29^{\circ} 47^{\prime} 44^{\prime \prime} \mathrm{N}, 31^{\circ} 14^{\prime} 23^{\prime \prime} \mathrm{E}\right)$; African chameleon, Chamaeleo africanus Laurenti, 1768 from Al Mansouria, Giza $\left(30^{\circ} 7^{\prime} 49^{\prime \prime} \mathrm{N}, 31^{\circ} 3^{\prime} 55^{\prime \prime} \mathrm{E}\right)$; and Nile monitor, Varanus niloticus Linnaeus, 1766 from Lake Nasser, $120 \mathrm{~km}$ South of Aswan $\left(23^{\circ} 25^{\prime} 25^{\prime \prime} \mathrm{N}\right.$, $32^{\circ} 55^{\prime} 38^{\prime \prime} \mathrm{E}$ ). 
Hosts were collected manually, euthanized and dissected. The body cavity of each host was examined and the oesophagus, stomach, small and large intestine of each lizard were examined separately for gastrointestinal helminths using a dissecting microscope (20X). For light microscopy, digenea and cestodes were flattened between two slides, fixed in $70 \%$ ethanol, stained with carmine, cleared in clove oil, and mounted in Canada balsam. Nematodes were fixed in $70 \%$ ethanol solution, cleared in lactophenol, and mounted in glycerol. Helminths were examined using an Olympus CX31 microscope, a Zeiss Stemi 2000-C microscope (4X,10X, 40X, 100X) and identified according to Anderson et al..$^{[10]}$, Bray et al. ${ }^{[11]}$, Gibson et $a .^{[12]}$, and Khalil et al. ${ }^{[13]}$. Taxonomy, identification and geographical distribution of the lizards were based on Baha El Din ${ }^{[2]}$ and Uetz et al. ${ }^{[14]}$
Ethical Consideration: Approval to conduct this study was obtained from the Institutional Animal Care and Use Committee (ICUC), Faculty of Science, Tanta University.

\section{RESULTS}

A total of 167 lizards belonging to six families (Agamidae, Phyllodactylidae, Gekkonidae, Lacertidae, Chamaeleonidae and Varanidae) were dissected for detection of gastrointestinal helminths. The total prevalence of infection with helminths was 35.9\%. Lizards were infected with sixteen species of helminths: six digenean species, four cestode species and six nematode species. Five lizard species were infected with two to seven helminth species. Data in table (1)

Table 1: Prevalence, intensity (mean \pm SD) and range of helminth species collected from lizards.

\begin{tabular}{|c|c|c|c|c|c|c|}
\hline Helminths & Stage & $\begin{array}{c}\text { Site of } \\
\text { infection }\end{array}$ & Host & $\begin{array}{l}\text { Prevalence } \\
\text { (No. infected/ } \\
\text { No. examined) }\end{array}$ & Intensity & Range \\
\hline \multicolumn{7}{|c|}{ Trematode (Digenea) } \\
\hline Pleurogenoides tener & Adult & SI & Chamaeleo africanus & $14.29 \%(3 / 21)$ & $66.33 \pm 54.50$ & $4-105$ \\
\hline Anchitrema sanguineum & Adult & SI & Chamaeleo africanus & $4.76 \%(1 / 21)$ & $1 \pm 0$ & 1 \\
\hline Cyclorchis varani & Adult & GB, SI & Varanus niloticus $\dagger$ & $31.25 \%(5 / 16)$ & $4.40 \pm 6.54$ & $1-16$ \\
\hline Prosthodendrium obtusum & Adult & SI & Chamaeleo africanus* & $38.10 \%(8 / 21)$ & $71.88 \pm 78.00$ & $3-210$ \\
\hline Mesostephanus milvi & Adult & SI & Varanus niloticus*† & $12.50 \%(2 / 16)$ & $3.50 \pm 3.53$ & $1-6$ \\
\hline Haplorchis pumilio & Adult & SI & Varanus niloticus*† & $43.75 \%(7 / 16)$ & $53.01 \pm 17.06$ & $1-134$ \\
\hline \multicolumn{7}{|c|}{ Cestode } \\
\hline Oochoristica mutabili & Adult & SI & $\begin{array}{l}\text { Pseudotrapelus sinaitus* } \\
\text { Trapelus mutabilis }{ }^{*} \\
\text { Tarentola m. mauritanica* }{ }^{*}\end{array}$ & $\begin{array}{c}30 \%(3 / 10) \\
27.78 \%(10 / 36) \\
9.38 \%(3 / 32)\end{array}$ & $\begin{array}{c}9.00 \pm 7.21 \\
15.8 \pm 16.06 \\
1 \pm 0\end{array}$ & $\begin{array}{c}1-15 \\
1-44 \\
1\end{array}$ \\
\hline Duthiersia fimbriata & Adult & SI & Varanus niloticus & $43.75 \%(7 / 16)$ & $1.43 \pm 1.13$ & $1-4$ \\
\hline Unidentified cestode species & Adult & SI & Varanus niloticus & $12.50 \%(2 / 16)$ & $5.5 \pm 0.71$ & $5-6$ \\
\hline Tetrathyridium & Larva & SI & $\begin{array}{l}\text { Pseudotrapelus sinaitus* } \\
\text { Trapelus mutabilis* }\end{array}$ & $\begin{array}{c}10 \%(1 / 10) \\
5.56 \%(2 / 36)\end{array}$ & $\begin{array}{c}49 \\
26 \pm 22.63\end{array}$ & $\begin{array}{c}49 \\
10-42\end{array}$ \\
\hline \multicolumn{7}{|c|}{ Nematode } \\
\hline Parapharyngodon micipsae & Adult & SI & $\begin{array}{l}\text { Pseudotrapelus sinaitus*† } \\
\text { Trapelus mutabilis* }{ }^{*}\end{array}$ & $\begin{array}{c}30 \%(3 / 10) \\
13.89 \%(5 / 36)\end{array}$ & $\begin{array}{c}2 \pm 1 \\
8.2 \pm 6.91\end{array}$ & $\begin{array}{c}1-3 \\
1-16\end{array}$ \\
\hline Pharyngodon inermicauda & Adult & SI & Tarentola m. mauritanica & $34.38 \%(11 / 32)$ & $5.27 \pm 5.06$ & $1-18$ \\
\hline Abbreviata leptosoma & Adult & Stomach, SI & $\begin{array}{l}\text { Pseudotrapelus sinaitus } \\
\text { Trapelus mutabilis }\end{array}$ & $\begin{array}{c}30 \%(3 / 10) \\
5.56 \%(2 / 36)\end{array}$ & $\begin{array}{l}4.33 \pm 3.21 \\
8.50 \pm 7.78\end{array}$ & $\begin{array}{c}2-8 \\
3-14\end{array}$ \\
\hline Thubunaea pudica & Adult & Stomach, SI & Trapelus mutabilis & $19.44 \%(7 / 36)$ & $4.14 \pm 5.79$ & $1-17$ \\
\hline Tanqua tiara & Adult & $\begin{array}{l}\text { Embeded } \\
\text { in stomach } \\
\text { mucosa }\end{array}$ & Varanus niloticus*十 & $12.50 \%(2 / 16)$ & $1.5 \pm 0.71$ & $1-2$ \\
\hline Spinicauda sonsinoi & Adult & LI, rectum & Chamaeleo africanus & $9.52 \%(2 / 21)$ & $1 \pm 0$ & 1 \\
\hline
\end{tabular}


shows the infected host number for each parasite species, prevalence of infection, intensity and range as well as, 10 new host and 10 new locality records.

The Nile monitor, $V$. niloticus was infected with three digeneans: Cyclorchis varani Price, 1936 (Opisthorchiidae), Mesostephanus milvi Yamaguti, 1939 (Cyathocotylidae) and Haplorchis pumilio (Looss, 1896) Looss, 1899 (Heterophyidae); an adult cestode, Duthiersia fimbriata Diesing, 1854 (Diphyllobothriidae), a tetrathyridium metacestode (Mesocestoididae), an unidentified cestode species; and one nematode species, Tanqua tiara (von Linstow, 1879) Blanchard, 1904 (Gnathostomatidae). The Sinai agama, $P$. sinaitus was infected with an adult cestode, Oochoristica mutabili Morsy et al., 2013 (Linstowiidae), a tetrathyridium metacestode; and two nematode species: Parapharyngodon micipsae Seurat, 1917 (Pharyngodonidae) and Abbreviata leptosome Gervais, 1848 (Physalopteridae). The desert agama, T. mutabilis wasinfected with an adult cestode, Oochoristica mutabili, a tetrathyridium metacestode; and three nematode species: Parapharyngodon micipsae, Thubunaea pudica Seurat, 1914 (Physalopteridae) and Abbreviata leptosoma. The African chameleon, C. africanus was infected with three digeneans: Pleurogenoides tener (Olsson, 1876) Travassos, 1921 (Pleurogenidae), Anchitrema sanguineum (Sonsino, 1894) Looss, 1899 (Anchitrematidae) and Prosthodendrium obtusum (Looss, 1896) Bhalerao, 1936 (Lecithodendriidae); and one nematode species, Spinicauda sonsinoi (Linstow, 1894) Travassos, 1920 (Heterakidae). The Moorish gecko, T. m. mauritanica was infected with an adult cestode, Oochoristica mutabili; and one nematode species, Pharyngodon inermicauda Baylis, 1923 (Pharyngodonidae). The Northern sand gecko, Tropiocolotes tripolitanus Peters, 1880 and the Bosk's fringe-fingered lizard or Bosc's fringe-toed lizard, Acanthodactylus boskianus Daudin, 1802 were free from helminths.

The most frequently infected hosts were $P$. sinaitus and $V$. niloticus with $80 \%$ infection rate, followed by $T$. m. mauritanica (43.75\%), T. mutabilis $(38.88 \%)$ and $C$. africanus (38.09\%). The prevalence of single infection with only one species of helminth was $20.96 \%$, followed by double $(8.98 \%)$, triple $(2.40 \%)$, and quadruple $(1.20 \%)$ infections.

\section{DISCUSSION}

Such variability in helminth community structure may result from variability in host diet, availability of intermediate host and host behavior which may have a direct effect on parasite transmission. In addition, the antagonistic response of intestinal infections of one group to others may affect the ability of some helminth to thrive even within their susceptible host. In our study, we found that $V$. niloticus, $T$. mutabilis and $C$. africanus are the most frequently infected hosts with multiple infections (digenea, cestodes and nematodes) at the same time. Varanus niloticus and T. mutabilis harbored six and four species of parasites respectively, the maximum number of species per host in each of them was four (in two hosts). Pseudotrapelus sinaitus harbored five species of parasites while the maximum number per host was three (in one host). Chamaeleo africanus harbored three species of parasites while the maximum number per host was three (in two hosts). Tarentola mauritanica mauritanica harbored two species, the maximum number per host was two (in three hosts).

The prevalence of single infection with only one species of helminth was highest than in mixed helminthic infections. This observation may reflect the antagonistic response of intestinal infections of one group to others and clarify the rarity of multiple infection. Saoud and Ramadan $^{[15]}$ observed that infections with specific trematode genera was antagonistic to infection with other genera and that this antagonism appears to be dependent on the species of host involved.

Pleurogenoides tener is a common digenean of amphibians and some reptile species ${ }^{[16]}$. In Egypt, only two species of Pleurogenoides (P. tener and P. medians) were reported ${ }^{[6,16]}$. The present specimen was very similar to P. tener reported previously by Groschaft and Moravec $^{[6]}$. The present identification is based on the ratio between oral and ventral sucker, and the extent and shape of the excretory vesicle. In Egypt, few studies reported the presence ${ }^{[6]}$ and life cycle ${ }^{[17]}$ of $P$. tener in lizards.

Anchitrema sanguineum is a worldwide digenean reported from reptiles, bats and shrews as definite hosts and humans as accidental host ${ }^{[11,18]}$. Only one specimen was found in our study. A full description was published by Saoud and Ramadan ${ }^{[19]}$ and El-Mahi ${ }^{[20]}$. Chamaeleo chamaeleon Linnaeus, $1758^{[6]}$, Chamaeleo vulgaris $(=C$. chamaeleon $)$ Khotenovsky, 1970 and Chamaeleo africanus Laurenti, 1768 (= C. basiliscus $)^{[21]}$ were reported as final hosts in Egypt.

Cyclorchis varani is a digenean originally described from $V$. niloticus in Africa ${ }^{[22]}$. The only species previously reported from Egypt was $C$. fayoumensis in the bile duct of the Egyptian Cobra, Najahaje ${ }^{[23]}$. The collected specimens resembles description of $C$. varani by Price ${ }^{[22]}$. The distinct constriction at the level of the ventral sucker, proximal part of uterus passing between ovary and testes or not, size of ventral sucker and testes arrangement are the significant characteristics to differentiate $C$. varani from $C$. campula and $C$. amphileuous ${ }^{[22]}$. Cyclorchis fayoumensis is differentiated from the present specimen by the large size of the body, unequal intestinal caeca, deeply branched testes, 
dissimilarities in the position of the genital pore, the bifurcation of the main excretory duct, and the small sized egg ${ }^{[23]}$. Lake Nasser, $120 \mathrm{~km}$ South of Aswan is a new locality record for $C$. varani.

Prosthodendrium obtusum is a digenean originally described from Chamaeleo basiliscus in Egypt ${ }^{[6]}$. The genus Prosthodendrium includes five species that were reported from Egyptian bats ${ }^{[2,25]}$. Reports on Prosthodenduim spp. from reptiles are few, only two were reported from Egypt ${ }^{[6]}$. Aspinose body, size of ventral sucker being smaller than oral sucker, ovary formed of 7-9 lobes and as wide as prostate mass, two groups of vitelline glands anterior to testes and intestinal caeca are the diagnostic characters of $P$. obtusum. Human infection with Prosthodendrium spp. were recorded in $\mathrm{Asia}^{[26,27]}$.

Mesostephanus milvi is a digenean, first described from Milvus migrans lineatus in Japan ${ }^{[28]}$, while M. milvi, $M$. appendiculatus, M. fajardensis, $M$. dotternsi and $M$. cubaensis were recorded in Egypt ${ }^{[29,30]}$. Our specimen differs from other species of the genus in having medium sized ventral sucker equal or sometimes smaller than the oral sucker; a muscular pharynx smaller than the oral sucker, short oesophagus; club-shaped cirrus pouch extending forward beyond the posterior testis to the right of it, distal part (post-prostatic) of the cirrus sac pocket about $1 / 5,1 / 6$ or $1 / 7$ of the length of the cirrus; vitelllaria are intertesticular partially or fully overlapping gonads; vaginal sphincter is absent and uterus with 6-10 large eggs ${ }^{[30-33]}$. This is the first report of M. milvi in V. niloticus in Egypt. To date, there are no records of $M$. milvi adult in monitors in the world.

Haplorchis pumilio is considered as a food-borne zoonotic digenean in many countries ${ }^{[4,35]}$ including Egypt $^{[36]}$. It completes its life cycle in fish of economic importance and in humans. The genus Haplorchis includes nine valid species; only three species, $H$. pumilio, $H$. taichui, and $H$. yokogawai were reported in Egypt $^{[37]}$. Species specific characteristics of $H$. pumilio are the structure and armature of the ventral sucker (crown of 32 to 40; I- or inverted capital V-shaped minute sclerites in $H$. pumilio, semi-lunar group of 12 16 long crescentic hollow spines in $H$. taichui, and 7074 to numerous tiny spines in $H$. yokogawai ${ }^{[37,38]}$. Our study designates a new host and locality records.

Oochoristica mutabili is considered a heteroxenous cestode that requires a suitable intermediate host ${ }^{[39]}$. The species of Oochoristica are cosmopolitan infecting more than 56 species of reptilian hosts, occasionally in mammals, and rare in amphibians ${ }^{[40-43]}$. Genus Oochoristica includes about 88 species, only 0 . mutabili, $O$. truncata, and $O$. fibrata were previously recorded in Egypt ${ }^{[9,41,44]}$. Our specimen is characterized by a scolex with circular suckers (105-150 u), distinct neck, 20-47 testes arranged in one cluster, and bilobed ovary. These morphological characteristics and measurements are similar to those reported by Morsy et al. ${ }^{[44]}$ in their description. Pseudotrapelus sinaitus and T. $\mathrm{m}$. mauritanica are new host records for 0 . mutabili, and Al Magarah in North Sinai, El-Dabaa desert, and $6^{\text {th }}$ October dessert near Giza are new geographical localities.

Tetrathyridium is the larval stage (metacestode) of the genus Mesocestoides. Species of Mesocestoides are unique among Cyclophyllidea in requiring three hosts in the life cycle ${ }^{[12,45]}$, the possibility of asexual reproduction of the tetrathyridial metacestodes by longitudinal fission ${ }^{[46]}$, and certain anatomical features that include the median ventral position of the genital atrium and the bipartite vitelline glands. Specific identification was not possible because of the absence of mature and gravid segments for this larval stage. Adult of Mesocestoides tapeworms have been reported previously in humans in $\mathrm{Korea}^{[47]}$ Japan $^{[48]}$ China $^{[49]}$, $\mathrm{USA}^{[50]}$ and Paraguay ${ }^{[51]}$. Cercopithecus albigularis Sykes, 1831 ${ }^{[52]}$, Acomys dimidiatus Cretzschmar, 1826 ${ }^{[53]}$, Acomys cahirinus É. Geoffrey, 1803, Acomys russatus Wagner, 1840, Dipodillus dasyurus Wagner, 1842, D. amoenus amoenus de Winton, 1902, Meriones crassus Sundevall, 1842, M. tristrami Thomas, $1892^{[54]}$, M. Shawi isis Thomas, 1919, Pachyuromys duprasi natronensis de Winton, 1903, Gerbillus gerbillus gerbillus Olivier, 1801 and G. pyramidium pyramidium I. Geoffroy, $1825^{[20,55]}$ were reported as hosts of tetrathyridium in Egypt. Our study is the first host record for tetrathyridium in $P$. sinaitus and T. mutabilis.

Duthiersia fimbriata cestode was described by Diesing from $V$. niloticus in Africa ${ }^{[56,57]}$. Duthiersia was reported in two forms: an Asiatic and an African form. The two forms can be morphologically distinguished on the basis of presence or absence of posterior pores in the scolex ${ }^{[57]}$. Few reports were recorded on African $D$. fimbriata $^{[58,59]}$. Woodland ${ }^{[56,59]}$ and Elmahy and Harras ${ }^{[60]}$ gave full descriptions for D. fimbriata.

Parapharyngodon micipsae is an oxyurid nematode characterized by four pairs of caudal papillae, presence of narrow weakly developed lateral alae, spicule of male with pointed or sharp tip, echinate cloacal lip present and the ovaries reaching anteriorly to the oesophagus base forming prominent coils around $\mathrm{it}^{[8,61]}$. This parasite is widely distributed ${ }^{[62]}$. Parapharyngodon includes more than 59 species $^{[63,64]}$. Parapharyngodon micipsae, P. bulbosus Linstow, 1899 and P. sceleratus Travassos, 1923 are the only species known from Egypt ${ }^{[8,65]}$. The recording of Parapharyngodon micipsae in our study represents new host and locality documentation.

Pharyngodon inermicauda is an oxyurid nematode originally described from Tarentola annularis Geoffroy Saint-Hilaire, 1827 in Cairo, Egypt ${ }^{[3]}$. Pharyngodon inermicauda and P. mamillatus Linstow, 1897 are the only reported species in Egypt ${ }^{[8]}$. The identification is based on the absence of male spicule, no inflation at 
the junction between lateral and caudal alae in male $P$. inermicauda, the anterior pair of postanal papillae not forked, lack of spines in the female caudal filament, and the pointed egg $^{[3,66]}$. Members of Oxyurida are monoxenous ${ }^{[67]}$.

Abbreviata leptosoma is a spirurid nematode, first described by Chabaud ${ }^{[68]}$ in the gut of Uromastiz acanthinurus in Algeria. Abbreviata spp. are cosmopolitan parasites with poorly recognized life cycle; final hosts comprise most vertebrates including amphibians, reptiles, birds and mammals, and intermediate hosts are invertebrates ${ }^{[68,69]}$. Characteristics of both male and female A. leptosoma ${ }^{[68]}$ include the cephalic denticulation with 5-8 elements between submedian teeth and lateral tooth, absence of denticulate crest at the dorsal and ventral angles of the mouth, presence of two branched uteri, and unequal dissimilar spicules.

Thubunaea pudica spirurid nematode has been previously reported in Egypt from different reptilian hosts; Scincus scincus ${ }^{[7]}$, Psammophis schokari ${ }^{[70]}$, Agama bibroni, Lacerta lepida, Psammodromus algirus, and Eumeces algeriensis ${ }^{[71]}$. Genus Thubunaea includes more than 23 species, two of them (T. pudica and $T$. dactyluris) were previously reported in Egypt ${ }^{[70,72,73]}$. Thubunaea pudica has simple equal lips, three teeth on each lip without ring of papillae or cuticular groove subtending the lips, short laterally compressed vestibule, male caudal papillae (about 32 papillae), and two subequal stout spicules ${ }^{[70,74]}$. Cockroaches and crickets are reservoir hosts of larval stage of Thubunaed spp. ${ }^{[75,76]}$, while reptiles were reported as final hosts ${ }^{[5]}$.

Tanqua tiara belongs to genus Tanqua R. Blanchard, 1904 of the family Gnathostomatidae. Reptiles (mainly Monitor lizards, Varanidae) and amphibians were reported as definite hosts for this genus ${ }^{[77]}$. There are ten described species of Tanqua, only one species ( $T$. tiara) was reported in Africa. It is differentiated from other species on the basis of the presence of head bulb divided into four swellings each with a ballonet, non-retractile head, uterus with 4 branches (3 extend anterior and one posterior), and vulva in the last quarter of the body ${ }^{[77,78]}$. Only three females were collected. Our study represents the first record of T. tiara in Egypt.

Spinicauda sonsinoi is an ascarid nematode belonging to family Heterakidae. The species was originally described from Laudakia stellio in Egypt ${ }^{[79]}$. Genus Spinicauda includes 17 species, of which only $S$. sonsinoi and $S$. grimmae were previously reported in Egypt $^{[4,8,9,70]}$. The length of male spicule, the number of caudal papillae, presence or absence of female caudal papillae, and presence or absence of a gubernaculum are the main characteristics to differentiate between species $^{[79,80]}$. The development of Spinicauda is monoxenous ${ }^{[67]}$. Chamaeleo africanus is a new host record.
Goldberg and Bursey ${ }^{[81]}$ reported that the difference in prevalence and intensity of helminth infection in reptiles is related to the attribution of dietary variation of host species. This is well illustrated in table (1), since infection of helminths requires various intermediate hosts which varies with the feeding habits and environment of the final hosts.

Chai ${ }^{[27]}$ marked 70 species of digenetic trematodes that infect humans. He classified them as blood flukes, liver flukes, lung flukes, and intestinal flukes based on their habitat in the definite host. Haplorchis, Prosthodendrium and Mesocestoides tetrathyridia reported in the present study are considered human infecting intestinal flukes ${ }^{[26,27]}$.

In conclusion, our study documented ten new host and ten new geographical locality- records in Egypt. These findings add significantly to the present information on helminths infecting lizards and their potential contribution to public health.

Acknowledgments: The authors would like to express their sincere thanks to Dr. Amal I Khalil Professor of Parasitology, Faculty of Science, Tanta University for her help in reviewing this work; and Professor Tim Littlewood, Director of Science at Natural History Museum, London, United Kingdom, for suppling us with literature.

Author contribution: RA Elmahy initiated the research idea, designed the study, identified the helminths, collected the references and wrote the manuscript. SF Harras contributed in practical work in Central laboratory in Zoology Department, and shared RA Elmahy in designing the study and identification of helminths.

Conflict of interest: Authors confirm that there are no known conflicts of interest associated with this study.

\section{REFERENCES}

1. Zahran MA, Willis AJ. Egypt: The Gift of the Nile. In: The Vegetation of Egypt. Springer, Dordrecht. 2009.

2. Baha El Din S. A Guide to the Reptiles and Amphibians of Egypt. Cairo and New York: The American University in Cairo Press. 2006.

3. Baylis HA. Report on a collection of parasitic nematodes, mainly from Egypt. Part II. Oxyuridae. Parasitol 1923; 15: 14-23.

4. Belle EA. Helminth parasites of reptiles, birds, and mammals in Egypt: IV. Four new species of oxyurid parasites from reptiles. Can J Zool 1957; 35: 163169.

5. Myers BJ, Kuntz RE, Wells WH. Helminth parasites of reptiles, birds, and mammals in Egypt: VII. Check list of nematodes collected from 1948 to 1955 . Can J Zool 1962; 40: 531-538. 
6. Groschaft J, Moravec F. Some trematodes and cestodes from amphibians and reptiles in Egypt. Vest Ces Spolec Zool 1983; 47: 241-249.

7. Moravec F, Barus V, Rysavy B. Some parasitic nematodes, excluding Heterakidae and Pharyngodonidae, from amphibians and reptiles in Egypt. Folia Parasitol 1987; 34: 255-267.

8. Moravec F, Barus V, Rysavy B. On parasitic nematodes of the families Heterakidae and Pharyngodonidae from reptiles in Egypt. Folia Parasitol 1987; 3: 269-280.

9. Al-Deen A, Al-Shareef MF, Saber SA. Ecological studies of Chalcides ocellatus (Forskal, 1775) and Hemidactylus turcicus (Linnaeus, 1758) from Egypt with special reference to helminthic parasites. J Egypt Soc Parasitol 1995; 25: 145-156.

10. Anderson RC, Chabaud AG, Willmott S. Keys to the Nematode Parasites of Vertebrates: Archival Volume (Nos). 1-10. Wallingford, Oxfordshire, UK: $\mathrm{CAB}$ International Publishing and The Natural History Museum; 2009.

11. Bray RA, Gibson DI, Jones A. Keys to the Trematoda. Vol. 3. Wallingford, Oxfordshire, UK: CAB International Publishing and The Natural History Museum; 2008.

12. Gibson D, Jones A, Bray R. Keys to the Trematoda, Volume 1. Wallingford, Oxfordshire, UK: CAB International Publishing and The Natural History Museum; 2002.

13. Khalil LF, Jones A, Bray RA. Keys to the Cestode Parasites of Vertebrates. Wallingford, Oxfordshire, UK: CAB International Publishing and The Natural History Museum; 1994.

14. Uetz P, Freed P, Hošek J. (Eds.). The Reptile database, http://www.reptile-database.org, accessed. 2019.

15. Saoud MFA, Ramadan MM. Studies on the helminth parasites of bats in Egypt and the factors influencing their occurrence with particular reference to digenetic Trematodes. Z Parasitenkd 1976; 51: 37-47.

16. Abdel-Gaber R, Maher S, Kamel R, El Deeb N. Supplementary studies of Pleurogenoides medians (Digenea: Lecithodendriidae) infecting the Marsh frog Rana Ridibunda (Amphibia: Ranidae) in Egypt. BJBAS 2017; 6: 154-159.

17. Macy RW. Life cycle of the digenetic trematode Pleurogenoides tener (Looss, 1898) (Lecithodendriidae). J Parasitol 1964; 50: 564-568.

18. Kusolsuk T, Paiboon N, Pubampen S, Maipanich W, Dekumyoy P, Waikagul J. Anchitrema sanguineum (Digenea: Anchitrematidae) accidentally found during colonoscopy of a patient with chronic abdominal pain: a case report. Korean J Parasitol 2009; 47: 167-170.

19. Saoud MFA, Ramadan MM. A review of the trematode genus Anchitrema Looss, 1899 (Dicrocoeliidae), with a redescription of Anchitrema sanguineum (Sonsino, 1894) and Anchitrema longiformis n. sp. from some Egyptian bats. Z Parasitenkd 1977; 54: 61-67.
20. El-Mahi RA. Flatworms of some wild mammals with special reference to Hymenolepidids from Egypt. Ph. D. Thesis, Faculty of Science, Tanta University, Egypt. 2014.

21. Gohar N. Liste des trématodes parasites et de leurs hôtes vertébrés signalés dans la Vallée du Nile. II. Ann Parasitol Hum Comp 1935; 13: 80-90.

22. Price EW. Two new trematodes from African reptiles. Proc Helminthol Soc Wash 1936; 3: 67-68.

23. Al-Bassel DAM. Description of new trematode parasite (Cyclorchis fayoumensis n. sp.) in the bile duct of the Egyptian cobra from Fayoum Governorate in Egypt, with a review to the genus Cyclorchis Luhe, 1908. J Union Arab Biol 1994; 2: 167-175.

24. Macy RW, Heyneman D, Kuntz RE. Records of trematodes of the families Lecithodendriidae, Dicrocoeliidae and Heterophyidae from Chiroptera collected in Egypt and Yemen, S. W. Arabia. Proc Helminthol Soc Wash 1961; 28: 13-17.

25. Saoud MFA, Ramadan MM. Studies on digenetic trematodes of the genus Prosthodendrium Dollfus, 1931 from some Egyptian bats. 1. Trematodes of the subgenus Prosthodendrium Dollfus, 1931. Folia Parasitol 1977; 24: 249-259.

26. Manning GS, Lertprasert P. Studies on the life cycle of Phaneropsolus bonnei and Prosthodendrium molenkampi in Thailand. Pathog Glob Health 1973; 67: 361-365.

27. Chai JY. Epidemiology of trematode infections. Adv Exp Med Biol 2014; 766: 241-292.

28. Yamaguti S. Studies on the helminth fauna of Japan. Part 25. Trematodes of birds, IV. Japan J Zool 1939; 8: 129-210.

29. Amer O. Redescription of Mesostephanus cubaensis Alegret, 1941 (Trematoda:Cyathocotylidae) from Varanus niloticus (Reptilia: Varanidae) in Assiut governorate, Egypt. J Egypt German Soc Zool 2010; 60: 37-47.

30. El-Gayar AK. Studies on some trematode parasites of stray dogs in Egypt with a key to the identification of intestinal trematodes of dogs. Vet Parasitol 2007; 144: 360-365.

31. Dubois G. Sur quelques Mesostephanus Lutz, 1935 (Strigeata: Cyathocotyloidea). Ann Parasitol (Paris) 1975; 50: 447-459.

32. Dubois, G. Les trématodes des genres Mesostephanus Lutz, 1935 et Mesostephanoides Dubois, 1951 (Strigeata: Cyathocotyloidea). Ann Parasitol (Paris) 1982; 57: 329-343.

33. Dubois G, Pearson JC. Les Strigeida (Trematoda) d'Egypte (Collection William H. Walls). Annales de Parasitologie 1963; 38: 77-91.

34. Sommerville C. The pathology of Haplorchis pumilio (Looss, 1896) infections in cultured tilapias. J Fish Dis 1982; 5: 243-250.

35. Huston DC, Worsham MD, Huffman DG, Ostrand KG. Infection of fishes, including threatened and endangered species by the trematode parasite 
Haplorchis pumilio (Looss, 1896) (Trematoda: Heterophyidae). BioInv Rec 2014; 3: 189-194.

36. Khalifa R, El-Naffar MK, Arafa MS. Studies on heterophyid cercariae from Assiut Province, Egypt. I. Notes on the life cycle of Haplorchis pumilio (Looss, 1896) with a discussion on previously described species. Acta Parasitol Pol 1977; 25: 2538.

37. Chai JY, Jung BK. Fishborne zoonotic heterophyid infections: An update. Food Water Parasitol 2017; 8-9: 33-63.

38. Kuntz RE, Chandler AC. Studies on Egyptian trematodes with special reference to the heterophyids of mammals. I. Adult flukes, with descriptions of Phagicola longicollis $\mathrm{n}$. sp, Cynodiplostomum Namrui n. sp., and a Stephanoprora from cats. J Parasitol 1956; 42: 445459.

39. Anderson RC. Nematode Parasites of Vertebrates. Their Development and Transmission. C.A.B. International, Wallingford, Oxon, U.K. 1992; 578.

40. Kennedy MJ, Killick LM, Beverley-Burton M. Oochoristica javaensis n. sp. (Eucestoda: Linstowiidae) from Gehyra mutilata and other gekkonid lizards (Lacertilia: Gekkonidae) from Java, Indonesia. Can J Zool 1982; 60: 2459-2463.

41. Okafor FC. Oochoristica agamae Baylis 1919 (Eucestoda, Linstowiidae) in one reptile and two bat species from Nsukka (Anambra State, Nigeria). Misc Zool 1988; 12: 11-15.

42. Bursey CR, Goldberg SR, Woolery DN. Oochoristica piankai sp. n. (Cestoda: Linstowiidae) and other helminths of Moloch horridus (Sauria: Agamidae) from Australia. J Helminthol Soc Wash 1996; 63: 215-221.

43. McAllister CT, Bursey CR. A new species of Oochoristica (Cyclophyllidae: Linstowidae) from non- native Mediterranean geckos, Hemidactylus turcicus (Sauria: Gekkonidae) from Texas, USA. Acta Parasitol 2017; 62: 296-305.

44. Morsy K, Ramadan NF, Al Hashimi S, Ali M, El Garhy MF. A new species of Oochoristica (Eucestoda: Cyclophyllidea) parasite of Agama mutabilis (Reptilia: Agamidae) from Egypt. J Egypt Soc Parasitol 2013; 43: 715-722.

45. Crosbie PR, Nadler SA, Platzer EG, Kerner C, Mariaux J, Boyce WM. Molecular systematics of Mesocestoides spp. (Cestoda: Mesocestoididae) from domestic dogs (Canis familiaris) and coyotes (Canis latris). J Parasitol 2000; 86: 350-357.

46. Specht D, Voge M. Asexual multiplication of Mesocestoides tetrathyridia in laboratory animals. J Parasitol 1965; 51: 268-272.

47. Choi WY, Kim BC, Choi HS. The first case of human infection with tapeworms of the genus Mesocestoides in Korea. Korean J Parasitol 1967; 5: 60-62.

48. Nagase K, Kani A, Totani T, Hamamoto T, Torikai K. Report of a human case of Mesocestoides lineatus and preliminary investigation into infective sources. Japan J Parasitol 1983; 32: 18.

49. Jin LG, Yi SH, Liu Z. The first case of human infection with Mesocestoides lineatus (Goeze, 1782) in Jilin Province. J Norman Bethune Univ Med Sci 1990; 4: 360-361.

50. Fuentes MV, Galan-Puchades MT, Malone JB. A new case report of human Mesocestoides infection in the United States. Am J Trop Med Hyg 2003; 68: 566567.

51. Beaver PC, Rolon FA. Proliferating larval cestode in a man in Paraguay. A case report and review. Am J Trop Med Hyg 1981; 30: 625-637.

52. Ezzat MAE, Gaafar SM. Tetrathyridium sp. in a Sykes' Monkey (Cercopithecus albigularis) from Giza Zoological Gardens, Egypt. J Parasitol 1951; 37: 392-394.

53. Wertheim G, Greenberg Z. Notes on helminth parasites of myomorph rodents from southern Sinai. J Helminthol 1970; 44: 243-252.

54. Wertheim G, Schmidt GD, Greenberg Z. Witenbergitaenia sinaica gen. n., sp. $n$. (Anoplocephalidae) and other cestodes from small mammals in Israel and in the Sinai Peninsula. Bull Mus Natl Hist Nat 1986; 8: 543-550.

55. Elmahi RA. On the cestodes of some mammals. M. Sc. Thesis, Faculty of Science, Tanta University, Egypt. 2008.

56. Woodland WNF. On the species of the genus Duthiersia Perrier, 1873 (Cestoda). Proc Zool Soc Lond 1938; 108: 17-36.

57. Woodland WNF. A revision of African and Asiatic forms of the genus Duthiersia (Cestoda). Pro Zool Soc Lond 1940; 110: 207-218.

58. Mettrick DF. Some cestodes of reptiles and amphibians from the Rhodesias. Pro Zool Soc Lond 1963; 141: 239-250.

59. Enabulele EE, Ozemoka HJ, Awharitoma AO, Aisien MSO. Parasitic infections of the African dwarf crocodile (Osteolaemus tetraspis) and the ornate Nile monitor (Varanus ornatus) from Nigeria. Acta Parasitol 2013; 58: 191-197.

60. Elmahy R, Harras S. Light and scanning electron microscopy of Duthiersia fimbriata Diesing, 1854 (Pseudophyllidea: Diphyllobothriidae) from the Nile monitor lizard (Varanus niloticus) from Egypt. Sylwan 2016; 160: 351-366.

61. Masova S, Barus V, Hodova I, Koubek P, Koubkova B. Redescription of Parapharyngodon micipsae (Seurat 1917) (Nematodes Pharyngodonidae) from the new host Tarentola parvicarinata Joger 1980 (Squamata: Gekkonidae). Trop Zool 2009; 22: 243-255.

62. Filho JA de A, Brito SV, Almeida W de 0, Morais DH, Ávila RW. A new species of Parapharyngodon (Nematoda: Pharyngodonidae) infecting Dermatonotus muelleri (Anura: Microhylidae) from Caatinga, Northeastern Brazil. Zootaxa 2015; 4012: 386-390. 
63. Bursey CR, Goldberg SR. Description of a new species of Parapharyngodon (Nematoda: Pharyngodonidae) from Mexico with a list of current species and key to species from the Panamanian region. J Parasitol 2015; 101: 374381.

64. Garduño-Montes de Oca EU, Mata-López R, LeónRègagnon V. Two new species of Parapharyngodon parasites of Sceloporus pyrocephalus, with a key to the species found in Mexico (Nematoda, Pharyngodonidae). Zookeys 2016; 559: 1-16.

65. Rabie SAH, Abd El-Latif MEZ, Mohamed NI, Abo Al-Hussein OF. Light and electron microscopic studies of Parapharyngodon sceleratus and Physaloptera sp. discovered in Some Reptiles of Qena Governorate, Egypt. Int J Sci Res 2014; 3: 2654-2661.

66. Bursey CR, Goldberg SR. Pharyngodon lepidodactylus sp. $\mathrm{n}$. (Nematoda: Pharyngodonidae) from the Mourning Gecko, Lepidodactylus lugubris (Lacertilia: Gekkonidae), from Hawaii. J Helminthol Soc Wash 1996; 63: 51-55.

67. Anderson RC. Nematode parasites of vertebrates. Their development and transmission. 2nd Edition, CABI Publishing, Wallingford, Oxon, UK, 2000; 650 pp.

68. Chabaud AG. Essai de revision des physalopteres parasites de reptiles. Ann Parasitol 1956; 31: 2952.

69. Bain O, MutafchievY, Junker K. Order Spirurida. In: Schmidt-Rhaesa, A. (Eds.) Handbook of Zoology: Gastrotricha, Cycloneuralia and Gnathifera. Volume 2. Nematoda. De Gruyter: Berlin- Boston 2014; 661-732.

70. Belle EA. Nematode parasites of Egyptian reptiles. A Thesis presented to the Faculty of Graduate Studies and Research of McGill University in partial fulfilment of the requirements for Master degree of Science. 1954.

71. Canaris AG, Gardner SL. Faculty Publications from the Harold W. Manter Laboratory of
Parasitology; 2003. Bibliography of Helminth Species Described from African Vertebrates 1800-1967. Paper 3.

72. Bursey CR, Goldberg SR. Thubunaea intestinalis n. sp. (Nematoda: Spiruroidea) from Yarrow's spiny lizard, Sceloporus jarrovii (Iguanidac), from Arizona, U.S.A. Trans Am Microsc Soc 1991; 110: 269- 278.

73. Ramallo G, Goldberg SR, Bursey CR, Castillo G, Acosta JC. Thubunaea eleodori sp. nov. (Nematoda: Physalopteridae) from Liolaemus eleodori (Sauria: Liolaemidae) from Argentina. Parasitol Res 2017; 116: 293-297.

74. Malan JR. Some helminths of South Africa lizards. Onderstepoort J Vet Sci Anim Ind 1939; 12: 2174.

75. Basir MA. On a larval nematode from an insect with a note on the genera Thubunaea Seurat, 1914 and Physalopteroides Wu and Liu, 1940. J Parasitol 1949; 35: 301-305.

76. Singh HS, Malti M, Chaudhary A. Larval form of the genus Thubunaea Seurat, 1914 from the body cavity of an insect, Supella sp., at Meerut (U.P.), India. J Appl Nat Sci 2011; 3: 54-57.

77. Baylis HA, Lane C. A Revision of the Nematode Family Gnathostomidae. Proc Zool Soc Lond $1920 ; 245-310$

78. Khera S. Nematode parasites of some Indian vertebrates. Indian J Helminthol 1954; 6: 27-113.

79. Incedogan $S$, Yildirimhan HS, Bursey CR. Helminth parasites of the ocellated skink Chalcides ocellatus (Forskal, 1775) (Scincidae) from Turkey. Comp Parasitol 2014; 81: 260-269.

80. Platt TR, Bush AO. Spinicauda regiensis n. sp. (Nematoda: Heterakoidea), a parasite of the ball python (Python regius). J Helminthol 1979; 53: 257-260.

81. Goldberg SR, Bursey CR. Physaloptera retusa (Nematoda: Physalopteridae) in naturally infected sagebrush lizards, Sceloporus graciosus (Iguanidae). J Wild Dis 1989; 25: 425-429. 